\title{
Surgical management and clinical outcomes of multiple-level symptomatic herniated thoracic discs
}

\section{Clinical article}

\author{
Mark E. Oppenlander, M.D., Justin C. Clark, M.D., James Kalyvas, M.D., \\ and Curtis A. Dickman, M.D. \\ Department of Neurological Surgery, Barrow Neurological Institute, St. Joseph's Hospital and Medical \\ Center, Phoenix, Arizona
}

\begin{abstract}
Object. Symptomatic herniated thoracic discs (HTDs) are rare, and patients infrequently require treatment of 2 or more disc levels. The authors assess the surgical management and outcomes of patients with multiple-level symptomatic HTDs.

Methods. A retrospective review of a prospectively maintained database was performed of 220 consecutive patients treated surgically for symptomatic HTDs. Clinical and surgical results were compared between patients with single-level disease and patients with multiple-level disease and also among the different approaches used for surgical decompression.

Results. Between 1992 and 2012, 56 patients (mean age 48 years; 26 male, 30 female) underwent 62 procedures for 130 HTDs. Forty-six patients $(82 \%)$ had myelopathy, and $36(64 \%)$ had thoracic radiculopathy; 24 patients had both conditions in varying degree. Symptom duration averaged 28 months. The surgical approach was dictated by disc size, consistency, and location. Twenty-three thoracotomy, 26 thoracoscopy, and 13 posterolateral procedures were performed. Five patients required a combination of approaches. Patients underwent 2-level $(n=44), 3-l e v e l(n=$ 7), 4-level $(n=4)$, or 5-level $(n=1)$ discectomies. Instrumented fusion was performed in 36 patients $(64 \%)$. Thirteen patients harbored 19 additional discs, which were deemed asymptomatic/nonoperative.

The mean hospital stay was 6.5 days. Complete disc resection was verified with postoperative imaging in every patient. The procedural complication rate was $23 \%$, and the nature of complications differed based on approach. No patients had surgery-related spinal cord injury or new myelopathy.

At a mean follow-up of 48 months, myelopathy and radiculopathy had resolved or improved at a rate of $85 \%$ and $92 \%$, respectively. Using a general linear model, preoperative symptom duration $(p=0.037)$ and perioperative hospital length of stay $(\mathrm{p}=0.004)$ emerged as negative predictors of myelopathy improvement. Most patients $(96 \%)$ were satisfied with the surgical results.

Compared with 164 patients who underwent single-level HTD decompression, patients requiring surgery for multiple-level HTDs were more often myelopathic $(p=0.012)$. Surgery for multiple-level HTDs was more likely to require a thoracotomy approach $(\mathrm{p}=0.00055)$ and instrumented fusion $(\mathrm{p}<0.0001)$ and resulted in greater blood loss $(\mathrm{p}=0.0036)$ and higher complication rates $(\mathrm{p}=0.0069)$. The rates of resolution for myelopathy $(\mathrm{p}=0.24)$ and radiculopathy $(\mathrm{p}=1.0)$, however, were similar between the 2 patient groups.

Conclusions. The management of multiple-level symptomatic HTDs is complex, requiring individualized clinical decision making. The surgical approaches must be selected to minimize manipulation of the compressed thoracic spinal cord, and a patient may require a combination of approaches. Excellent surgical results can be achieved in this unique and challenging patient population.
\end{abstract}

(http://thejns.org/doi/abs/10.3171/2013.8.SPINE121041)

\section{KEY WORDS - multiple herniated thoracic discs • myelopathy $\quad$ thoracoscopy $\bullet$ thoracic radiculopathy $\quad \bullet \quad$ thoracic microdiscectomy $\bullet$ thoracotomy}

$\mathrm{S}$ YMPTOMATIC herniated thoracic discs (HTDs) are rare, with an estimated annual incidence of 1 per million patients ${ }^{13}$ and comprising $0.1 \%-4 \%$ of all disc herniations., ${ }^{3,38}$ In addition, patients infrequently require treatment of 2 or more disc levels. To date, scant literature exists, consisting of case reports and small clini-

\footnotetext{
Abbreviations used in this paper: HTD = herniated thoracic disc; $\mathrm{VAS}=$ visual analog scale.
}

cal series, $4,8,10,15,16,28,34-36,39,42,44$ which address the unique diagnostic features, surgical strategies, and outcomes of patients with multiple-level HTDs.

Despite their rarity, multiple-level HTDs may present with devastating myelopathy or severe thoracic radicular pain, in which cases surgical decompression is the definitive treatment option. ${ }^{6,12}$ Historically, thoracic laminectomy resulted in unacceptable complications. ${ }^{5,26,31,37}$ Subsequent surgical techniques were thus developed with 


\section{Management of multilevel symptomatic herniated thoracic discs}

the aim of minimizing manipulation to the thoracic spinal cord; these may be categorized as posterolateral or anterolateral approaches. The posterolateral approaches, including transfacet, transpedicular, and costotransversectomy techniques, are appropriate for paracentral or lateral HTDs. ${ }^{4,8,15}$ Anterolateral approaches, consisting of thoracotomy or thoracoscopy, best address large, midline, calcified disc herniations. ${ }^{10,16,28,34,35,39,45}$

We report our experience on the management of patients with multiple-level symptomatic HTDs, treated via thoracotomy, thoracoscopy, and/or posterolateral approaches. Patient characteristics, surgical variables, and outcomes are compared among the different approaches and also to those of an unmatched cohort of patients undergoing single-level HTD decompression. In this manner, we attempt to identify the unique surgical challenges and clinical outcomes of this patient cohort.

\section{Methods}

\section{Patient Population}

Between 1992 and 2012, 56 consecutive patients (mean age 48 years, range 26-76 years; 26 male, 30 female) underwent 62 procedures for the treatment of 130 HTDs performed by the senior author (C.A.D.). Followup averaged 48 months (range 1-174 months). Forty-four (79\%) of 56 patients had more than 6 months of follow-up. A prospectively collected database was maintained from office visits and during hospitalization to capture patient and surgical characteristics and outcome data, including responses to questionnaires, medical records, clinical examinations, and radiographic findings. The database was supplemented with telephone interviews when appropriate. The retrospective review was performed by 2 of the authors (M.E.O. and J.C.C.). The institutional review board of St. Joseph's Hospital and Medical Center approved this retrospective case series.

During the same study period, surgical treatment of a single-level HTD was performed in 164 patients (mean age 50 years; mean follow-up 43 months; 125 [76\%] of 164 patients with $>6$ months of follow-up). Of all patients requiring surgery, 36 harbored an additional 59 HTDs, which were deemed asymptomatic and nonoperative. Over 200 additional patients were referred for evaluation of their HTDs and treated nonoperatively.

\section{Clinical Evaluation}

Most patients were selected for surgery from the outpatient clinic. Many represented out-of-state and international referrals. One patient $(2 \%)$ presented acutely through the emergency department. Evaluation of the HTDs was performed by MRI, CT myelography, or both. Computed tomography myelography was performed in patients when the HTDs appeared large or calcified. Imaging studies included views up to and including the clivus to correctly localize the pathology. In addition, preoperative chest radiography was performed in all patients to confirm the rib count.

A neurological examination was performed in all patients by an attending neurosurgeon at preoperative and postoperative visits. Patients with myelopathy were classified according to the Frankel grading scale. ${ }^{23}$ Pain was rated from 0 to 10 by the patient based on a visual analog scale (VAS). Final myelopathy and pain scores were tabulated at the last follow-up. In addition, patients were asked postoperatively to comment on their satisfaction with the surgery and willingness to undergo the surgery again.

\section{Surgical Indications and Approaches}

Myelopathy related to HTDs was the strongest indication for surgery. In patients with clinical signs and symptoms of thoracic myelopathy who harbored multiplelevel HTDs, a specific HTD was considered for surgical treatment if it indented and deformed the thoracic spinal cord, especially in the presence of T2 cord signal change or thinning of the spinal cord. Surgical treatment was recommended for all patients with myelopathy due to compressive HTDs.

In patients with thoracic radiculopathy, an HTD was considered symptomatic if eccentrically located to the ipsilateral side and at a spinal level matching the patient's symptoms. If no concurrent myelopathy was present, surgery was recommended only if the symptoms were disabling and after failure of extensive nonoperative measures. Mimicking pathologies were excluded, including rib fracture, costochondritis, cardiac disease, or cholelithiasis.

The surgical approach was dictated by disc size, consistency, and location. The choice of approach evolved over the study period based on the senior author's (C.A.D.'s) experience. An anterior approach was selected for central herniated discs that crossed the midline and compressed the ventral surface of the spinal cord. Central, ossified, giant, intradural HTDs were approached anteriorly, usually with thoracotomy and corpectomies. Thoracotomy was also preferred for 3 or more contiguous central HTDs. Central, soft or calcified, moderate-sized discs were usually approached via thoracoscopy. The goal of the anterior approaches is to create a corridor in the vertebral bodies, into which the HTDs are removed, thereby eliminating any manipulation of the already-compromised thoracic spinal cord.

Herniated thoracic discs occupying the lateral spinal canal were considered for posterolateral decompression, including transfacet, transpedicular, and costotransversectomy techniques. More than one approach was required in 5 patients $(9 \%)$ with multiple-level HTDs to most directly and safely address each individual disc. In all approaches, instrumented fusion was considered at the index operation based on the amount of bony removal needed for the discectomy. The thoracotomy, 7,9,10,18,28,34,39 thora-

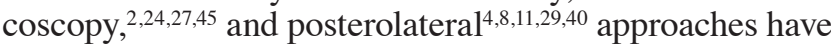
been previously described in full detail. In addition, the management strategy for transdural HTDs has been previously described..$^{25}$

\section{Postoperative Imaging}

Postoperative MRI and/or CT imaging was obtained in all patients to confirm complete disc resection. Two patients $(4 \%)$ required return to the operating room for 


\section{E. Oppenlander et al.}

residual disc. One additional patient had a residual calcified disc revealed by intraoperative imaging with an Iso-C unit, which subsequently guided further discectomy.

\section{Statistical Analysis}

Mean age, hospital length of stay, and operative blood loss were analyzed as continuous variables. Patient sex, presenting symptoms, HTD characteristics, procedure type, need for instrumented fusion, need for transfusion, and presence of complication or symptom resolution were analyzed as categorical variables. Unpaired t-test and 1-way ANOVA were used to compare continuous variables. Fisher exact test and chi-square test were used to analyze categorical variables.

To evaluate the prognostic value of the variables under consideration, a general linear model was used to predict a dichotomous positive postoperative myelopathy outcome, based on Frankel grades. Variables entered into the model included age, sex, preoperative symptom duration, number of symptomatic HTDs, disc characteristics, and perioperative hospital length of stay.

\section{Results}

\section{Symptomatology}

The most common presenting symptom was myelopathy (46 patients [82\%]), followed by radiculopathy (36 patients [63\%]). Twenty-four (43\%) of these patients had varying degrees of both myelopathy and radiculopathy. Twenty-seven patients (48\%) complained of local thoracic back pain in combination with myelopathy and/or radiculopathy, but no patient who underwent surgery presented exclusively with back pain. Seventeen patients (30\%) presented with bowel/bladder incontinence.

Patients were symptomatic for an average of 28 months (range $0.1-180$ months) prior to surgery and had attempted an average of 3 conservative measures (range 0-9) before undergoing operative treatment. Inciting events, such as an episode of trauma, which precipitated symptoms were identified in 24 patients $(43 \%)$.

The single patient who presented acutely through the emergency department was a 35-year-old woman with progressive myelopathy over 3 days, consisting of lowerextremity weakness, numbness, and bladder incontinence. She was found to have 2 central, giant, calcified HTDs at T11-12 and T12-L1. She underwent thoracotomy for discectomy of the affected levels with T-12 corpectomy and T11-L1 anterolateral fixation and fusion. The patient recited no history of trauma or other inciting event.

\section{Discs}

Patients underwent 2-level $(n=44)$, 3-level $(n=7)$, 4-level $(n=4)$, or 5-level $(n=1)$ discectomies, for a total of 130 symptomatic disc levels requiring decompression. The most common affected level was T7-8 (31 [24\%] of 130), followed by T8-9 (23 [18\%] of 130) and T6-7 (22 [17\%] of 130) (Fig. 1). Fourteen giant discs (occupying > $40 \%$ of the spinal canal), 37 calcified or ossified discs, and 5 transdural discs were identified, constituting $11 \%, 28 \%$, and $4 \%$ of the operative disc levels, respectively. Seven- teen patients $(30 \%)$ harbored 31 discs $(24 \%)$, which were noncontiguous and isolated from the other levels requiring decompression.

\section{Surgical Procedures}

Twenty-three thoracotomy, 26 thoracoscopy, and 13 posterolateral procedures were performed (Table 1). In general, a thoracotomy was used for more extensive pathology. Longer-segment discectomies were more likely to require a thoracotomy: $9(39 \%)$ of the thoracotomy procedures addressed 3 or more disc levels, whereas 1 thoracoscopy (4\%) and 1 posterolateral procedure $(8 \%)$ addressed 3 or more disc levels $(\mathrm{p}=0.0031)$. Twentyeight $(47 \%)$ of 59 discs approached via thoracotomy were densely calcified or ossified, compared with $5(10 \%)$ of 48 discs approached via thoracoscopy or $4(17 \%)$ of 23 discs approached posterolaterally ( $\mathrm{p}<0.0001)$. In addition, thoracotomy addressed more giant discs $(n=12)$ and transdural discs $(n=5)$ compared with thoracoscopy (1 giant disc, 0 transdural discs) or posterolateral (1 giant disc, 0 transdural discs) approaches.

Accordingly, thoracotomy procedures carried increased risk of surgical morbidity. Patients undergoing thoracotomy had increased blood loss (mean $1661 \mathrm{ml}$, range $150-5500 \mathrm{ml}$ ) compared with the cohorts undergoing thoracoscopy (mean $362 \mathrm{ml}$, range 150-1500 ml) or posterolateral (mean $496 \mathrm{ml}$, range 100-2500 ml) procedures $(\mathrm{p}=0.0002)$. Transfusion of red blood cells was required in 5 thoracotomy (22\%), 1 thoracoscopic (4\%), and 2 posterolateral $(15 \%)$ procedures. Patients undergoing thoracotomy required a longer hospital length of stay (mean 9 days, range 5-20 days) compared with the thoracoscopy (mean 5 days, range 3-9 days) and posterolateral (mean 4 days, range $2-8$ days) approaches $(\mathrm{p}<0.0001)$.

Instrumented fusion was performed in 36 patients (64\%). Two of these patients underwent combined-approach discectomies requiring fixation at the time of each approach. Instrumented fusion was more likely to be required during thoracotomy (22 [96\%] of 23 procedures) compared with thoracoscopy (9 [35\%] of 26 procedures) or posterolateral (7 [54\%] of 13 procedures) approaches $(p=0.0001)$. None of the patients who were treated with fixation and fusion developed nonunion or instrumentation-related complications.

\section{Combined Approaches}

A combination of approaches was required in 5 patients. Three underwent planned, staged procedures (mean time between procedures 3 days [range 0-6 days]). Two of these patients presented with bilateral thoracic radiculopathy and underwent posterolateral decompression of a paracentral HTD, followed by a thoracoscopic approach for decompression of a central HTD eccentrically located to the contralateral side of the spinal canal. The third patient had undergone a right-sided thoracoscopic discectomy of T7-8 for thoracic myelopathy. Her symptoms were improving until 4 months postoperatively, when she developed new myelopathy and new thoracic radiculopathy. Imaging revealed a new central T8-9 HTD contributing to her myelopathy, as well as a new right-lateral T6-7 
Management of multilevel symptomatic herniated thoracic discs

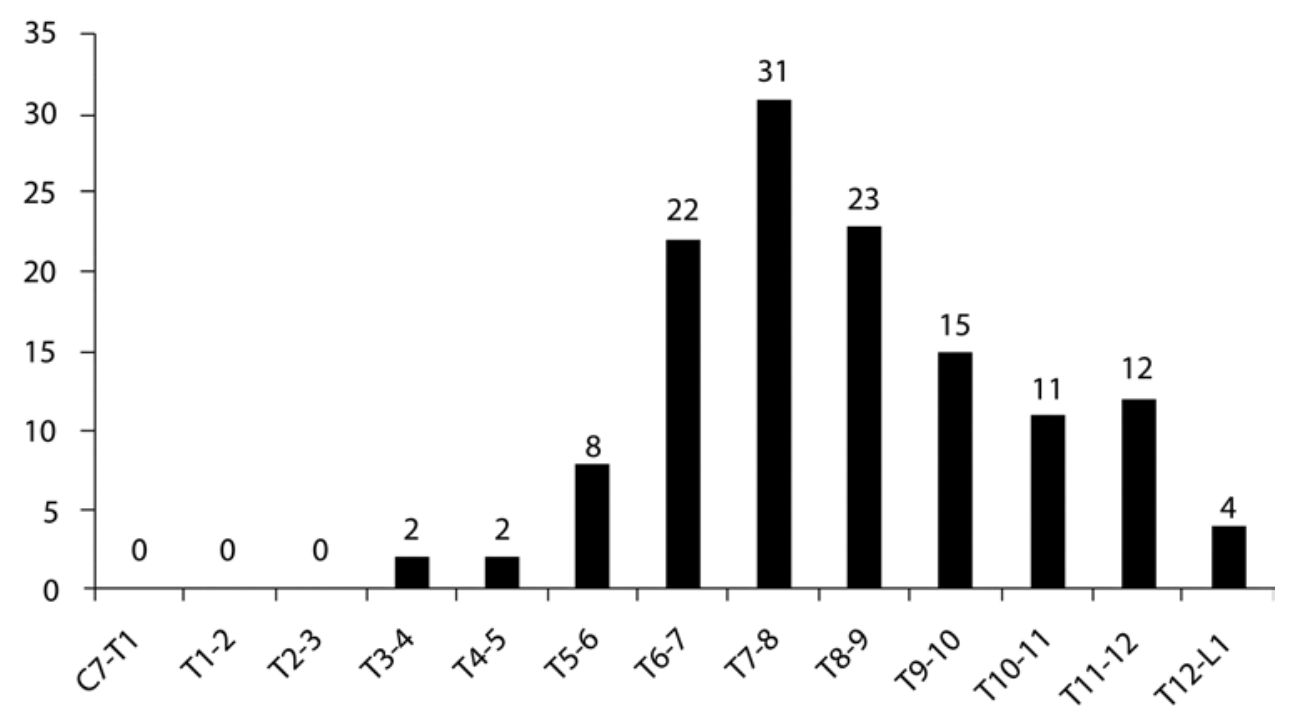

FIG. 1. Graph showing number of herniated thoracic discs (y axis) stratified by spinal level (x axis).

HTD responsible for the new radiculopathy. She therefore underwent planned, staged decompressive procedures: a left-sided thoracoscopic T8-9 discectomy followed 2 days later by a posterolateral transpedicular T6-7 discectomy.

The 2 additional patients requiring combined approaches had undergone previous thoracic discectomies and developed delayed postoperative symptomatology attributable to a new HTD. The mean time between discectomy procedures in patients with delayed postopera- tive herniation of an additional level was 41 months (range 4-69 months).

\section{Multiple-Level Versus Single-Level HTD Surgery}

The cohort of 56 patients requiring multiple-level HTD surgery was compared with an unmatched cohort of 164 patients who underwent single-level HTD decompression (Table 2). The multiple-level cohort had a larger proportion of males than the single-level cohort (26 of 56

TABLE 1: Comparison of approaches utilized for multiple-level HTD decompression*

\begin{tabular}{|c|c|c|c|c|}
\hline \multirow[b]{2}{*}{ Variable } & \multicolumn{3}{|c|}{ Approach (\%) } & \multirow[b]{2}{*}{$\mathrm{p}$ Value } \\
\hline & Thoracotomy & Thoracoscopy & Posterolateral & \\
\hline no. of procedures & 23 & 26 & 13 & \\
\hline no. of discs & 59 & 48 & 23 & \\
\hline$\geq 3$ levels & $9(39)$ & $1(4)$ & $1(8)$ & 0.0031 \\
\hline \multicolumn{5}{|l|}{ discs } \\
\hline calcified & $28(47)$ & $5(10)$ & $4(17)$ & $<0.0001$ \\
\hline giant & $12(20)$ & $1(2)$ & $1(4)$ & 0.0056 \\
\hline transdural & $5(8)$ & 0 & 0 & \\
\hline mean EBL (ml) & 1661 & 362 & 496 & 0.0002 \\
\hline transfusion & 5 & 1 & 2 & 0.168 \\
\hline instrumented fusion & $22(96)$ & $9(35)$ & $7(54)$ & 0.0001 \\
\hline mean LOS (days) & 9 & 5 & 4 & $<0.0001$ \\
\hline \multicolumn{5}{|l|}{ complications } \\
\hline total & $9(39)$ & $4(15)$ & $1(8)$ & 0.049 \\
\hline pleural effusion (requiring drainage) & $3(13)$ & $2(8)$ & 0 & 0.38 \\
\hline chylothorax & $2(9)$ & 0 & 0 & 0.17 \\
\hline residual disc (requiring subsequent op) & $2(9)$ & 0 & 0 & 0.17 \\
\hline incidental durotomy & $1(4)$ & $1(4)$ & $1(8)$ & 0.86 \\
\hline delayed fixation/fusion & 0 & $1(4)$ & 0 & 0.49 \\
\hline miscellaneous/minor & $1(4)$ & 0 & 0 & 0.42 \\
\hline
\end{tabular}

* $\mathrm{EBL}=$ estimated blood loss; $\mathrm{LOS}=$ length of stay. 
M. E. Oppenlander et al.

TABLE 2: Clinical and surgical data of multiple-level versus single-level HTD patients*

\begin{tabular}{|c|c|c|c|c|}
\hline \multirow[b]{2}{*}{ Variable } & \multicolumn{2}{|c|}{ HTD Group (\%) } & \multirow[b]{2}{*}{ Total (\%) } & \multirow[b]{2}{*}{$p$ Value } \\
\hline & Multilevel & Single-Level & & \\
\hline patients & $56(25)$ & $164(75)$ & 220 & \\
\hline $\mathrm{M} / \mathrm{F}$ ratio & 0.87 & 0.71 & 0.75 & 0.0087 \\
\hline mean age (yrs) & 48 & 50 & 49 & 0.33 \\
\hline mean follow-up (mos) & 48 & 43 & 45 & \\
\hline \multicolumn{5}{|l|}{ symptoms } \\
\hline myelopathy & $46(82)$ & $105(64)$ & $151(68)$ & 0.012 \\
\hline radiculopathy & $36(64)$ & $99(60)$ & $135(61)$ & 0.64 \\
\hline mean duration (mos) & 28 & 29 & 29 & 0.74 \\
\hline \multicolumn{5}{|l|}{ no. of discs } \\
\hline total & 130 & 164 & 294 & \\
\hline giant & $14(11)$ & $29(18)$ & $43(15)$ & 0.10 \\
\hline calcified & $37(28)$ & $50(30)$ & $87(30)$ & 0.80 \\
\hline transdural & $5(4)$ & $14(9)$ & $19(7)$ & \\
\hline nonoperative discs & 19 & 40 & 59 & \\
\hline total no. of ops & 62 & 164 & 226 & \\
\hline thoracotomy & 23 & 25 & 48 & 0.00055 \\
\hline thoracoscopy & 26 & 110 & 136 & 0.00077 \\
\hline posterolateral & 13 & 29 & 42 & 0.70 \\
\hline instrumented fusion & $36(64)$ & $42(24)$ & $78(35)$ & $<0.0001$ \\
\hline mean EBL (ml) & 872 & 487 & 593 & 0.0036 \\
\hline need for transfusion & $8 / 62 \dagger(13)$ & $15 / 164(9)$ & $23 / 226$ & 0.46 \\
\hline mean LOS (days) & 6.5 & 5.3 & 5.7 & 0.023 \\
\hline complications & $14 / 62 \dagger(23)$ & $17 / 164(10)$ & $31 / 226(14)$ & 0.0069 \\
\hline \multicolumn{5}{|c|}{ resolution or improvement of Sx } \\
\hline myelopathy & $39(85)$ & $84(80)$ & $123(81)$ & 0.24 \\
\hline radiculopathy & $33(92)$ & $91(91)$ & $124(92)$ & 1.0 \\
\hline
\end{tabular}

* Sx = symptom.

$\dagger$ Number of procedures 62 .

vs 68 of 164 patients, respectively, $p=0.0087$ ) and presented more often with myelopathy (82\% vs $64 \%$, respectively, $\mathrm{p}=0.012$ ). Patients with multiple-level HTDs were more likely to require thoracotomy ( 23 of 62 vs 25 of 164 procedures, respectively, $\mathrm{p}=0.00055$ ) and instrumented fusion (36 of 56 vs 42 of 164 patients, respectively, p < 0.0001), whereas single-level HTDs were more often decompressed via thoracoscopy (110 of 164 procedures, $\mathrm{p}=$ 0.00077 ) without instrumented fusion. The mean surgical blood loss ( $872 \mathrm{vs} 487 \mathrm{ml}$, respectively, $\mathrm{p}=0.0036)$, length of hospital stay (6.5 vs 5.3 days, respectively, $\mathrm{p}=0.023$ ), and rate of complications (23\% vs $10 \%$, respectively, $\mathrm{p}=$ $0.0069)$ were all greater in the multiple-level HTD cohort, but the rates of resolution for myelopathy $(p=0.24)$ and radiculopathy $(\mathrm{p}=1.0)$ were comparable between the 2 groups.

\section{Patient Outcomes}

A total of 46 patients presented with myelopathy. At last follow-up, 39 patients (85\%) improved in their Frankel grade. Seven patients $(15 \%)$ maintained the same grade function. Of those in whom the Frankel grade remained the same, 2 patients (4\%) showed improvement in their motor function below threshold to change Frankel grades. No patient with multiple-level HTDs had worsening of myelopathy or new myelopathy postoperatively (Table 3 ).

A general linear model was used to predict a dichotomous positive myelopathy outcome in the 46 patients who presented with myelopathy. The adjusted R-squared for this model was 0.35 , meaning 35\% of the variation in Frankel grade improvement was explained by this model. Odds

TABLE 3: Outcomes of 46 patients with preoperative myelopathy treated for multiple-level HTDs*

\begin{tabular}{cccc}
\hline & \multicolumn{3}{c}{ Postop Frankel Grade (no. of patients) } \\
\cline { 2 - 4 } Preop Frankel Grade & C & D & E \\
\hline C & 0 & 7 & 1 \\
D & 0 & 7 & 31 \\
E & 0 & 0 & 0 \\
\hline
\end{tabular}

* Patients presented with Frankel Grade C or D myelopathy. At last follow-up, patients' function was Frankel Grade D or E. 
TABLE 4: General linear model predicting myelopathy outcomes in 46 patients with multiple-level HTDs and preoperative myelopathy*

\begin{tabular}{lcccc}
\hline \multicolumn{1}{c}{ Variable } & OR & $95 \% \mathrm{Cl}$ & $\mathrm{p}$ Value & $\begin{array}{c}\text { Effect } \\
\text { Size† }\end{array}$ \\
\hline age & 1.004 & $0.994-1.013$ & 0.412 & 0.019 \\
sex & 1.101 & $0.908-1.335$ & 0.316 & 0.029 \\
Sx duration (mos) & 0.997 & $0.995-1.000$ & 0.037 & 0.118 \\
HTD levels & 0.927 & $0.850-1.010$ & 0.081 & 0.084 \\
giant & 1.232 & $0.938-1.618$ & 0.126 & 0.065 \\
calcified & 0.956 & $0.739-1.237$ & 0.725 & 0.004 \\
LOS (days) & 0.951 & $0.920-0.983$ & 0.004 & 0.216 \\
\hline
\end{tabular}

* Myelopathy outcomes are based on Frankel grades. Preoperative symptom duration and perioperative hospital LOS emerged as negative predictors of myelopathy improvement. The number of symptomatic HTDs emerged as a negative predictor but at the trend level. $\dagger$ Partial $\eta^{2}$.

ratios are shown in Table 4. Preoperative symptom duration and perioperative hospital length of stay emerged as negative predictors of postoperative myelopathy improvement ( $p=0.037$ and $p=0.004$, respectively). The number of symptomatic HTD levels also emerged as a negative predictor but at the trend level $(\mathrm{p}=0.081)$. Interpretation of odds ratios of less than 1 can be more intuitive in the inverse. Each additional month of symptom duration was associated with a 0.99 odds of myelopathy improvement or a $1.003(0.3 \%)$ increase in the odds of no improvement in postoperative Frankel grade. Each additional day in the hospital was associated with a 0.95 odds or $5 \%$ increase in odds of no myelopathy improvement.

Of the 36 patients presenting with radiculopathy, the average VAS severity of pain was 8 . Postoperatively, 33 patients $(92 \%)$ had resolution or improvement of their symptoms, including $23(64 \%)$ with complete resolution and $10(28 \%)$ with improvement of radiculopathic pain. Three patients $(8 \%)$ had no change in pain, and no patient had worsened pain.

Seventeen patients presented with bowel/bladder incontinence. Ten (59\%) had complete resolution of symptoms, and $3(18 \%)$ reported improvement of incontinence. Two patients $(12 \%)$ had no change in these symptoms. No patient reported postoperative worsening of continence.

Patients were asked postoperatively to comment on their satisfaction with and willingness to undergo the surgery again. Fifty-two of the 56 patients were available for questioning. Of these, 50 patients $(96 \%)$ would be willing to undergo the operation again if needed.

\section{Complications}

The nature of complications differed based on approach (Table 1). Complications associated with thoracotomy and thoracoscopy were primarily related to operating through the thoracic cavity, whereas posterolateral approaches demonstrated no such complications. Thoracotomy was associated with more complications $(n=9$ [39\%]) compared with thoracoscopy $(n=4$ [15\%]) or pos- terolateral $(\mathrm{n}=1[8 \%])$ approaches $(\mathrm{p}=0.049)$. Pleural effusions requiring drainage occurred in 3 thoracotomytreated patients and 2 thoracoscopy-treated patients. Two patients who underwent thoracotomy sustained a chylothorax requiring open repair. Two patients were returned to the operating room for treatment of residual disc; both had undergone thoracotomy. Three incidental durotomies occurred during resection of discs that were not transdural: 1 incidental durotomy was accounted for in each approach cohort, and all were treated with lumbar spinal fluid drainage. One patient developed a compression fracture at the index level after thoracoscopy and underwent thoracotomy 4 months later for corpectomy and instrumented fusion. One patient who underwent thoracotomy and instrumented fusion was returned to the operating room the following day for repositioning of a screw. No patients had surgery-related spinal cord injury or new myelopathy.

\section{Discussion}

In 1954, Svien and Karavitis were the first to report on a patient requiring decompression for multiple-level HTDs. ${ }^{42}$ Few reports in the literature have described the treatment of patients with multiple-level symptomatic HTDs, and none comprehensively addresses the different surgical management strategies and outcomes in a large group of patients. ${ }^{1,2,4,7-11,15,16,18-22,24,27-30,32-36,38-45}$

The current series of 56 consecutive patients requiring operative decompression of 130 symptomatic HTDs represents the largest to date. Although 17 of the current study's patients had been previously reported, ${ }^{24,45}$ unique aspects of their management had not been highlighted. Additionally, specific comparisons of approaches within a cohort of patients with multiple-level HTDs, as well as direct comparisons to single-level HTD patients, have not previously been reported in the literature.

\section{Clinical Features}

The decision to surgically decompress any HTD is dictated by a patient's symptoms and correlative pathology. A priority is given to patients presenting with myelopathy, as the majority of patients $(82 \%)$ in this study had function that was Frankel Grade D or worse on presentation. If the patient presents with thoracic radiculopathy, the HTD must correspond to the clinical level of symptoms. No patient in this series was offered surgery for local back pain alone, and multiple conservative measures must have failed before the patient was offered surgical decompression for pain syndromes.

When patients were found to have multiple-level HTDs, care was taken to identify only those discs which matched the patients' clinical symptoms. Accordingly, 17 patients in the present series who required surgery for multiple-level HTDs underwent decompression of noncontiguous levels. Compared with the literature, only 15 patients undergoing noncontiguous, multiple-level HTD decompression have previously been reported. , $7,11,22,28,34,35$ In addition, when considering our global cohort of patients with single-level and multiple-level HTDs, a substantial number of HTDs $(n=59)$ were deemed asymptomatic 
and nonoperative. Therefore, all surgical HTDs in myelopathic patients abutted, distorted, and deformed the spinal cord, while the surgical HTDs in radiculopathic patients correlated to the level of symptomatology.

The protean clinical manifestations of HTDs may present a diagnostic dilemma. Diagnosis is often delayed, with potential to exacerbate a clinical myelopathy. Indeed, the average duration of symptomatology before surgical intervention in this series reached 28 months. In contrast, we report only 1 patient (2\%) with multiple-level HTDs presenting with acute myelopathy. Such acute presentations occur infrequently. ${ }^{14,17}$ Cornips et al. ${ }^{17}$ identified an acute presentation with myelopathy in approximately $4 \%$ of their HTD series: 5 of the 8 patients with acute presentation had multiple-level HTDs, all HTDs were located below T9-10, and the majority of HTDs were giant and calcified. This clinical profile matches that of our patient, adding to the notion that HTDs may be present and clinically silent, indeed even calcified, long before an acute presentation.

\section{Surgical Considerations}

Although previous studies have included patients with multiple-level HTDs within a larger cohort of patients undergoing single-level HTD decompressions, ${ }^{1,2,7,9,11,12,18-20,27}$, 29,38,41,43,45 no direct comparisons between these patient populations exist. Compared with an unmatched cohort of single-level HTD patients, decompression for multiple-level HTDs in the current study more often required thoracotomy $(\mathrm{p}=0.00055)$ and instrumented fusion $(\mathrm{p}<$ $0.0001)$, entailed greater surgical blood loss $(\mathrm{p}=0.0036)$, and resulted in a greater number of nonneurological complications $(p=0.0069)$. Conversely, surgery for a singlelevel HTD was more often able to be accomplished via thoracoscopy $(p=0.00077)$ without instrumented fusion.

It is important to emphasize that this large group of complex patients was treated surgically with no neurological morbidity and with excellent long-term neurological outcomes. No patients developed surgery-related spinal cord injuries. Eighty-five percent of patients with myelopathy had an improved Frankel grade. We attribute these excellent neurological results to careful selection of the operative approaches and meticulous surgical techniques.

Three primary surgical approaches (thoracotomy, thoracoscopy, and posterolateral techniques) were used to optimize safe access to and most effectively decompress the HTDs. The most important goal when choosing a surgical approach is to minimize manipulation of an alreadycompromised thoracic spinal cord.

An anterior approach was selected for central herniated discs that crossed the midline and compressed the ventral surface of the spinal cord. It is dangerous to use posterolateral approaches for central herniated discs, which are deforming the spinal cord in the midline and displacing it posteriorly, because of the risk of causing spinal cord injury. When a central herniated disc is present, it is safest to use an anterolateral approach, either thoracoscopy or thoracotomy. Posterolateral approaches are suited for paracentral or lateral herniated discs that do not cross the midline.

Thoracotomy allows direct visualization of and ac- cess to central herniated discs, enabling the disc to be pulled away from the spinal cord and into a trough created by the bony corpectomy. This approach is therefore best suited for very large, densely calcified or ossified central HTDs and for patients with 3 or more contiguous central HTDs. Likewise, in their series of 12 patients with multiple-level HTDs, Ohnishi et al. performed a thoracotomy for all patients undergoing decompression. ${ }^{34}$ Half of these patients harbored 3 or more HTDs. Similarly, Ayhan et al. used a transthoracic approach for all 27 patients with centrally located HTDs, all of whom presented with myelopathy and 5 of whom had multiple-level HTDs.?

In the present series, significantly more giant $(\mathrm{p}=$ $0.0056)$ and calcified or ossified $(\mathrm{p}<0.0001)$ discs were treated via thoracotomy with wide corpectomies, necessitating more extensive bony removal and therefore requiring significantly greater use of instrumented fusion ( $\mathrm{p}=$ 0.0001 ). In addition, discectomies of 3 or more levels were more often approached via thoracotomy if the herniated discs were centrally located, anterior to the spinal cord $(p=0.0031)$. Harboring more complex pathology, patients undergoing thoracotomy in our series had a greater length of hospital stay ( $p<0.0001)$ and higher number of nonneurological complications $(p=0.049)$ than those undergoing other approaches.

Thoracoscopy allows anterior decompression of multiple-level HTDs with significantly less surgical morbidity than thoracotomy. Thoracoscopy enables direct anterolateral access to the HTDs but with a more minimally invasive technique. We prefer thoracoscopy to treat 1-level or 2-level central HTDs, which are at contiguous levels, as long as the discs are not giant, transdural, or ossified. Disadvantages of thoracoscopy include the practice required to acquire endoscopic surgical skills, mastering the learning curve ${ }^{45}$ and greater complexity when treating multiple disc levels. We attribute the excellent results for thoracoscopy in our series to careful patient selection and extensive experience with this surgical approach. Thoracoscopically treated patients in this series were less likely to have 3 or more affected levels $(p=0.0031)$ and the HTDs were less likely to be giant $(\mathrm{p}=0.0056)$ or densely calcified or ossified $(\mathrm{p}<0.0001)$. While few studies of thoracoscopic microdiscectomy include patients with multiple-level HTDs within a larger cohort of single-level HTDs, ${ }^{2,27,45}$ no prior reports exist that highlight the thoracoscopic treatment of patients with multiple-level disease.

Only 3 prior studies have highlighted the posterolateral approach for treatment of multiple-level HTDs., ${ }^{4,8,15}$ Most recently, Arnold et al. used a transfacet approach for treatment of 15 patients with 32 symptomatic laterally oriented HTDs presenting with myelopathy and/or radiculopathy. ${ }^{4}$ They reported excellent clinical results with minimal complications. In the current series, a combination of posterolateral techniques were used for HTDs oriented laterally in the spinal canal with only 1 complication (incidental durotomy with no permanent sequelae).

We additionally provide detailed reports of planned, staged procedures with a combination of surgical approaches in patients with multiple-level HTDs. These 3 patients presented with symptoms distinctly attributable to different HTDs. Again, the location of the HTDs within the spinal canal, along with disc size and consistency, dic- 


\section{Management of multilevel symptomatic herniated thoracic discs}

tated the safest and most effective approaches in these patients. Two patients with bilateral radiculopathy underwent posterolateral decompression for lateral HTDs, followed by thoracoscopic microdiscectomy for central HTDs. The third patient underwent thoracoscopy first, giving priority to the HTD that was causing her myelopathy.

\section{Outcomes and Complications}

Excellent long-term postoperative clinical and neurological results were achieved in patients with multiplelevel HTDs. The results of treatment in patients with myelopathy and thoracic radiculopathy were equivalent to the outcomes of patients who had single-level HTDs, with equivalent rates of symptom resolution between the 2 patient cohorts. On closer inspection, a greater proportion of patients in the multiple-level HTD cohort presented with myelopathy, required a more invasive thoracotomy approach, and sustained greater operative morbidity, but these patients recovered with clinical results similar to those of the single-level HTD cohort. The end results can therefore justify a more extensive procedure required to treat these complicated patients. In addition, patients were overall very satisfied with their decision to undergo operative treatment of their multiple-level HTDs, as $96 \%$ of patients were willing to undergo the operation again if needed.

In an attempt to identify variables predictive of clinical outcome, a general linear model identified preoperative symptom duration and hospital length of stay as significant predictors of postoperative myelopathy in a negative association. This relationship makes intuitive sense; a patient with longer-standing myelopathy or spinal cord injury may have a higher likelihood that this injury will remain permanent, and a longer stay in the hospital after surgery may be a result of poorer neurological status.

The nonneurological complication rate within the multiple-level HTD cohort was higher compared with the single-level cohort. Nine of the 14 complications occurred in the thoracotomy group. This is likely a function of more severe pathology treated through this approach, and the greater invasiveness of an open thoracotomy. As such, 5 of the 9 complications in the thoracotomy group were directly related to operating through the pleural space ( 3 pleural effusions, 2 chyle leaks). Thoracoscopy and posterolateral approaches were associated with significantly lower complication rates $(\mathrm{p}=0.049)$.

It is noteworthy that postoperative neurological decline occurred in 3 patients within the single-level HTD cohort but in no patients with multiple-level HTDs. These patients have been previously described. ${ }^{25,45}$ The complications occurred after thoracoscopy ( 2 patients) and posterolateral (1 patient) approaches. As Hott et al. described in 2005, the thoracotomy approach is preferred for giant HTDs and no neurological complications were associated with thoracotomy in their series of 20 giant HTDs. ${ }^{25}$ Because 12 of 14 giant HTDs were approached via thoracotomy in the our series, patients with multiple-level HTDs thus avoided postoperative neurological deterioration.

A meaningful comparison of the current study's complications with previous reports is difficult given the heterogeneity across reports of patient populations, patholo- gies, and approaches. Ayhan et al. reported 6 major complications and 5 minor complications within a cohort of 28 patients undergoing thoracotomy for HTD decompression (5 patients with multiple-level HTDs), for a complication rate of 39\%.? Ohnishi et al. reported 1 pneumonia and 1 chylothorax after thoracotomy in 12 patients with multiple-level HTDs. ${ }^{34}$ Johnson et al. reported on 36 patients (6 with 2-level HTDs) undergoing thoracoscopic discectomy and 8 patients (7 with multilevel HTDs $[\geq 3]$ ) undergoing open thoracotomy for discectomy. ${ }^{27}$ Their complication rates were $31 \%$ in the thoracoscopy group and greater than $100 \%$ ( $>1$ complication per patient) in the thoracotomy group. Stillerman et al. reported a complication rate of $14.6 \%$ in treating 71 patients (10 with multiple-level HTDs) undergoing HTD decompression via thoracotomy or posterolateral approaches. ${ }^{41}$ This rate, however, was not subdivided by approach or the presence of multilevel disease. Bransford et al. reported complications in 6 of 18 patients (9 patients with multiple-level HTDs) undergoing a modified transfacet pedicle-sparing HTD decompression, ${ }^{11}$ whereas Arnold et al. reported 2 complications in the treatment of 15 patients with multiple-level HTDs undergoing transfacet thoracic discectomies. ${ }^{4}$ Taken together, the current series' overall complication rate of $23 \%$ is within the wide range of historical data, but we also provide further information by reporting complications based on approach and the presence of multilevel disease.

\section{Study Limitations}

This study was undertaken in an effort to describe treatment options and outcomes in a large group of patients with multiple-level symptomatic HTDs. However, several limitations exist. The retrospective review exposes this study to inherent observational biases. Despite this, every effort was made to provide an accurate account from this prospectively collected database of each reported variable and adverse event.

The Frankel grading scale was developed as a measure of acute spinal cord injury, but it has successfully been adopted as a measure of myelopathy. ${ }^{46,47}$ We therefore preferred to use the prospectively maintained Frankel grades rather than retrospectively assigning an alternate scale. In addition, bladder function was not formerly assessed via postvoid residuals, and an encompassing scale of myelopathy with motor and sphincter scores was not prospectively maintained. However, the improvement in myelopathy based on the Frankel scale provides evidence that these patients do benefit from surgical intervention, and it is possible that an even higher rate of symptom improvement would be noted using a more sensitive measure of myelopathy.

Additionally, a significant selection bias was present in the comparison groups, and without randomization equal distribution of known and unknown confounders cannot be assured. However, randomization would only be beneficial for patients with clinical equipoise, thus severely limiting numbers of this already rare pathology. If such an effort were to be undertaken, a randomized trial evaluating treatment options for HTD pathology would likely require multiinstitutional cooperation. 


\section{Conclusions}

Patients with multiple-level symptomatic HTDs can be treated safely and have excellent neurological results if targeted surgical approaches, which create an unobstructed corridor of access to the HTDs, are used. Manipulation of the compressed spinal cord is thereby minimized. The selection of thoracotomy, thoracoscopy, and/or posterolateral approaches depends on the position, size, and consistency of the HTDs and on the surgeon's knowledge and experience. A combination of approaches may be necessary in a subset of patients.

Patients requiring surgery for multiple-level HTDs are more often myelopathic compared with patients requiring single-level HTD decompression, and they more often require thoracotomy for decompression. The management of multiple-level symptomatic HTDs is complex, requiring individualized clinical decision making. Excellent long-term clinical results can be achieved in this unique and challenging patient population.

\section{Acknowledgment}

We would like to thank Kristina Chapple, Ph.D., for her statistical and editorial support.

\section{Disclosure}

Dr. Dickman reports being a consultant to Medtronic, being a patent holder at Medtronic, and receiving book royalties from Thieme Publishing. The other authors report no conflict of interest concerning the materials or methods used in this study or the findings specified in this paper.

Author contributions to the study and manuscript preparation include the following. Conception and design: Dickman, Oppenlander. Acquisition of data: Oppenlander, Clark. Analysis and interpretation of data: Dickman, Oppenlander. Drafting the article: Oppenlander. Critically revising the article: all authors. Reviewed submitted version of manuscript: all authors. Approved the final version of the manuscript on behalf of all authors: Dickman. Statistical analysis: Oppenlander. Administrative/technical/material support: Oppenlander, Clark. Study supervision: Dickman.

\section{References}

1. Abbott KH, Retter RH: Protrusions of thoracic intervertebral disks. Neurology 6:1-10, 1956

2. Anand N, Regan JJ: Video-assisted thoracoscopic surgery for thoracic disc disease: Classification and outcome study of 100 consecutive cases with a 2-year minimum follow-up period. Spine (Phila Pa 1976) 27:871-879, 2002

3. Arce CA, Dohrmann GJ: Herniated thoracic disks. Neurol Clin 3:383-392, 1985

4. Arnold PM, Johnson PL, Anderson KK: Surgical management of multiple thoracic disc herniations via a transfacet approach: a report of 15 cases. Clinial article. J Neurosurg Spine 15:7681,2011

5. Arseni C, Nash F: Thoracic intervertebral disc protrusion: a clinical study. J Neurosurg 17:418-430, 1960

6. Awwad EE, Martin DS, Smith KR Jr, Baker BK: Asymptomatic versus symptomatic herniated thoracic discs: their frequency and characteristics as detected by computed tomography after myelography. Neurosurgery 28:180-186, 1991

7. Ayhan S, Nelson C, Gok B, Petteys RJ, Wolinsky JP, Witham $\mathrm{TF}$, et al: Transthoracic surgical treatment for centrally located thoracic disc herniations presenting with myelopathy: a 5-year institutional experience. J Spinal Disord Tech 23:79-88, 2010
8. Bhole R, Gilmer RE: Two-level thoracic disc herniation. Clin Orthop Relat Res (190):129-131, 1984

9. Bohlman HH,Zdeblick TA: Anterior excision of herniated thoracic discs. J Bone Joint Surg Am 70:1038-1047, 1988

10. Boriani S, Biagini R, De lure F, Rocella P, Veronesi V, Dalbuono S, et al: Two-level thoracic disc herniation. Spine (Phila Pa 1976) 19:2461-2466, 1994

11. Bransford R, Zhang F, Bellabarba C, Konodi M, Chapman JR: Early experience treating thoracic disc herniations using a modified transfacet pedicle-sparing decompression and fusion. Clinical article. J Neurosurg Spine 12:221-231, 2010

12. Brown CW, Deffer PA Jr, Akmakjian J, Donaldson DH, Brugman JL: The natural history of thoracic disc herniation. Spine (Phila Pa 1976) 17 (6 Suppl):S97-S102, 1992

13. Carson J, Gumpert J, Jefferson A: Diagnosis and treatment of thoracic intervertebral disc protrusions. J Neurol Neurosurg Psychiatry 34:68-77, 1971

14. Chen CF, Chang MC, Liu CL, Chen TH: Acute noncontiguous multiple-level thoracic disc herniations with myelopathy: a case report. Spine (Phila Pa 1976) 29:E157-E160, 2004

15. Chin LS, Black KL, Hoff JT: Multiple thoracic disc herniations. Case report. J Neurosurg 66:290-292, 1987

16. Coleman RJ, Hamlyn PJ, Butler P: Anterior spinal surgery for multiple thoracic disc herniations. Br J Neurosurg 4:541-543, 1990

17. Cornips EM, Janssen ML, Beuls EA: Thoracic disc herniation and acute myelopathy: clinical presentation, neuroimaging findings, surgical considerations, and outcome. Clinical article. J Neurosurg Spine 14:520-528, 2011

18. Currier BL, Eismont FJ, Green BA: Transthoracic disc excision and fusion for herniated thoracic discs. Spine (Phila Pa 1976) 19:323-328, 1994

19. Dietze DD Jr, Fessler RG: Thoracic disc herniations. Neurosurg Clin N Am 4:75-90, 1993

20. el-Kalliny M, Tew JM Jr, van Loveren H, Dunsker S: Surgical approaches to thoracic disc herniations. Acta Neurochir (Wien) 111:22-32, 1991

21. Fessler RG: Lateral extracavitary approach to resection of central thoracic disc protrusion. J Neurosurg 74:A355, 1991 (Abstract)

22. Francavilla TL, Powers A, Dina T, Rizzoli HV: MR imaging of thoracic disk herniations. J Comput Assist Tomogr 11:10621065,1987

23. Frankel HL, Hancock DO, Hyslop G, Melzak J, Michaelis LS, Ungar GH, et al: The value of postural reduction in the initial management of closed injuries of the spine with paraplegia and tetraplegia. Part I. Paraplegia 7:179-192, 1969

24. Han PP, Kenny K, Dickman CA: Thoracoscopic approaches to the thoracic spine: experience with 241 surgical procedures. Neurosurgery 51 (5 Suppl):S88-S95, 2002

25. Hott JS, Feiz-Erfan I, Kenny K, Dickman CA: Surgical management of giant herniated thoracic discs: analysis of 20 cases. J Neurosurg Spine 3:191-197, 2005

26. Hulme A: The surgical approach to thoracic intervertebral disc protrusions. J Neurol Neurosurg Psychiatry 23:133-137, 1960

27. Johnson JP, Filler AG, McBride DQ: Endoscopic thoracic discectomy. Neurosurg Focus 9(4):E11, 2000

28. Korovessis PG, Stamatakis M, Michael A, Baikousis A: Threelevel thoracic disc herniation: case report and review of the literature. Eur Spine J 6:74-76, 1997

29. Le Roux PD, Haglund MM, Harris AB: Thoracic disc disease: experience with the transpedicular approach in twenty consecutive patients. Neurosurgery 33:58-66, 1993

30. Lesoin F, Rousseaux M, Autricque A, Reesaul Y, Villette L, Clarisse J, et al: Thoracic disc herniations: evolution in the approach and indications. Acta Neurochir (Wien) 80:30-34, 1986

31. Logue V: Thoracic intervertebral disc prolapse with spinal 


\section{Management of multilevel symptomatic herniated thoracic discs}

cord compression. J Neurol Neurosurg Psychiatry 15:227241,1952

32. Love JG, Schorn VG: Thoracic-disk protrusions. JAMA 191: 627-631, 1965

33. O'Leary PF, Camins MB, Polifroni NV, Floman Y: Thoracic disc disease. Clinical manifestations and surgical treatment. Bull Hosp Jt Dis Orthop Inst 44:27-40, 1984

34. Ohnishi K, Miyamoto K, Kanamori Y, Kodama H, Hosoe H, Shimizu K: Anterior decompression and fusion for multiple thoracic disc herniation. J Bone Joint Surg Br 87:356-360, 2005

35. Okada Y, Shimizu K, Ido K, Kotani S: Multiple thoracic disc herniations: case report and review of the literature. Spinal Cord 35:183-186, 1997

36. Peker S, Akkurt C, Ozcan OE: Multiple thoracic disc herniations. Acta Neurochir (Wien) 107:167-170, 1990

37. Perot PL Jr, Munro DD: Transthoracic removal of midline thoracic disc protrusions causing spinal cord compression. J Neurosurg 31:452-458, 1969

38. Ridenour TR, Haddad SF, Hitchon PW, Piper J, Traynelis VC, VanGilder JC: Herniated thoracic disks: treatment and outcome. J Spinal Disord 6:218-224, 1993

39. Shikata J, Yamamuro T, Iida H, Kashiwagi N: Multiple thoracic disc herniations: case report. Neurosurgery 22:1068-1070, 1988

40. Simpson JM, Silveri CP, Simeone FA, Balderston RA, An HS: Thoracic disc herniation. Re-evaluation of the posterior approach using a modified costotransversectomy. Spine (Phila Pa 1976) 18:1872-1877, 1993

41. Stillerman CB, Chen TC, Couldwell WT, Zhang W, Weiss MH: Experience in the surgical management of 82 symptomatic herniated thoracic discs and review of the literature. J Neurosurg 88: 623-633, 1998
42. Svien HJ, Karavitis AL: Multiple protrusions of intervertebral disks in the upper thoracic region: report of case. Proc Staff Meet Mayo Clin 29:375-378, 1954

43. Uribe JS, Smith WD, Pimenta L, Härtl R, Dakwar E, Modhia $\mathrm{UM}$, et al: Minimally invasive lateral approach for symptomatic thoracic disc herniation: initial multicenter clinical experience. Clinical article. J Neurosurg Spine 16:264-279, 2012

44. Van Landingham JH: Herniation of thoracic intervertebral discs with spinal cord compression in kyphosis dorsalis juvenilis (Scheuermann's disease). Case report. J Neurosurg 11: 327-329, 1954

45. Wait SD, Fox DJ Jr, Kenny KJ, Dickman CA: Thoracoscopic resection of symptomatic herniated thoracic discs: clinical results in 121 patients. Spine (Phila Pa 1976) 37:35-40, 2012

46. Williams BJ, Fox BD, Sciubba DM, Suki D, Tu SM, Kuban D, et al: Surgical management of prostate cancer metastatic to the spine. Clinical article. J Neurosurg Spine 10:414-422, 2009

47. Zhu Q, Qian M, Xiao J, Wu Z, Wang Y, Zhang J: Myelopathy due to calcified meningiomas of the thoracic spine: minimum 3 -year follow-up after surgical treatment. Clinical article. J Neurosurg Spine 18:436-442, 2013

Manuscript submitted November 12, 2012.

Accepted August 27, 2013.

Please include this information when citing this paper: published online October 11, 2013; DOI: 10.3171/2013.8.SPINE121041.

Address correspondence to: Curtis A. Dickman, M.D., Neuroscience Publications, Barrow Neurological Institute, St. Joseph's Hospital and Medical Center, 350 W. Thomas Rd., Phoenix, AZ 85013.email: neuropub@dignityhealth.org. 